\title{
SIGNIFICADO ATRIBUIDO POR EDUCADORAS DE PÁRVULOS A LOS CONTEXTOS PARA EL APRENDIZAJE EN EL NIVEL DE SALA CUNA ${ }^{1}$
}

Assigned meaning as nursery teachers to learning contexts in the nursery school level

Significado atribuído por professoras de pré escola aos contextos para a aprendizagem em nível de jardim infantil

\section{Carolina Flores-Lueg}

Universidad del Bío-Bío, Chile. Fono:+56 42 2463491. Correo electrónico: cflores@ ubiobio.cl

\section{Ana Gajardo-Rodríguez}

Universidad del Bío-Bío, Chile. Fono:+56 42 2463115. Correo electrónico: agajardo@ubiobio.cl

\section{Lucía Navarrete- Troncoso}

Universidad del Bío-Bío, Chile. Fono:+56 42 2463488. Correo electrónico: lnavarre@ubiobio.cl

\section{Resumen}

Se presenta una investigación que estuvo centrada en determinar el significado que le atribuyen las Educadoras de Párvulos de sala cuna a la implementación en de cada uno de los contextos para el aprendizaje explicitados en las Bases Curriculares de la Educación Parvularia chilena. Se utilizó un enfoque cualitativo a través de diseño de estudio de casos múltiples, donde se seleccionaron intencionalmente a tres educadoras que desempeñan su labor atendiendo a niños y niñas menores de dos años. Los resultados obtenidos evidencian que las educadoras operacionalizan los contextos para el aprendizaje a partir de las apreciaciones, creencias e interpretaciones que han ido construyendo a lo largo de su experiencia profesional, más que en base a las orientaciones que se proporcionan en el marco curricular vigente para el nivel.

Palabras Claves: Educación Parvularia, Bases Curriculares, contextos para el aprendizaje, nivel sala cuna.

\section{Abstract}

\footnotetext{
1 Este artículo forma parte del Proyecto de Investigación $\mathrm{N}^{\circ} 090123$ 1/ I, adjudicado por las investigadoras en el marco de la postulación de Proyectos de Iniciación de la Universidad del Bío-Bío. Chile.
} 
The research presented was centered in determining the meaning that nursery teachers from nursery school, give to the implementation in each one of the learning contexts explicited in Bases Curriculares of chilean nursery teaching. A qualitative approach was used through the study design of multiple cases, where three nursery teachers who work with boys and girls under two years old, were selected intentionally. The obtained results evidence that the teachers operationalize the learning contexts starting from the appraisal, beliefs and interpretations that have been building through their professional experience, more than with the curricular basis orientations, that curriculum framework provide.

KEYWORDS: Nursery teaching, Bases Curriculares, learning contexts, nursery school level.

\section{Resumo}

Pesquisa que esteve centrada em determinar o significado que atribuem as Professoras de Pré Escola para a implementação em cada um dos contextos de aprendizagem declarados nas Bases Curriculares da Educação Infantil chilena. Utilizou-se um enfoque qualitativo através de desenho de estudo de casos múltiplos, no qual se selecionaram intencionalmente a três educadoras que desempenham seu labor atendendo a crianças menores de dois anos. Os resultados obtidos evidenciam que as educadoras operacionalizam os contextos para a aprendizagem a partir das apreciações, crenças e interpretações que foram construídas ao longo de sua experiencia profissional, mas que em base as orientações que se proporcionam no marco curricular vigente para o nível.

\section{Palavras Chave: Educação Infantil, Bases Curriculares, contextos para a} aprendizagem, nível jardim infantil.

\section{Introducción}

Actualmente la Educación Parvularia ha llegado a constituirse en uno de los niveles formativos considerado como foco de atención para las diferentes políticas sociales, educativas y económicas que se han venido implementando desde hace algún tiempo no sólo en Chile, sino también en diversos países latinoamericanos (Bravo y Morales, 2012). Estas acciones se fundamentan sobre la base de diversos aportes teóricos y empíricos que ofrecen antecedentes respecto a la importancia de los seis primeros años de vida en el desarrollo posterior de un ser humano (Katz, 2005; MINEDUC, 2014; 
Peralta, 2005; Pitluk, 2001; Ramírez, Patiño y Gamboa, 2014). En esta misma línea, se destacan algunos resultados de investigaciones que dan cuenta de la incidencia de la Educación Parvularia en los niveles educativos posteriores, principalmente resultados referidos a la disminución en las tasas de repetición y de deserción escolar (Young y Fujimoto, 2004), así como también en el mejoramiento de los resultados escolares (Aguilar y Tansani, 2012; Bennet y Paredes, 2013; Banco Mundial, 2011; Reveco y Mella, 2004), pero esta incidencia positiva solo tiene lugar en la medida en que los párvulos reciban una educación de calidad, de lo contrario incluso puede llegar a ser perjudicial para su desarrollo socioemocional y cognitivo (Belsky, 2005).

Por lo anterior, se puede desprender que la asistencia de los niños y niñas al Jardín Infantil o a un centro educativo formal tiene una repercusión directa en los resultados escolares que podrían alcanzar en los niveles educativos siguientes. No obstante a los aportes científicos actuales sobre la infancia, es necesario recordar que el reconocimiento sobre la importancia de considerar la educación infantil bajo una perspectiva pedagógica y no meramente asistencial, comienza a gestarse en el siglo XVI a partir de las ideas planteadas por los grandes precursores de la Educación Parvularia, tales como Conmenio (1592-1670); Rousseau (1742-1778); Decroly (18711932); Pestalozzi (1746-1827); Montessori (1870 -1952); Freinet (1896-1966); Dewey (1859-1952), entre otros, pues desde ese entonces ya se dejaba de manifiesto la necesidad de considerar al niño(a) como sujeto activo, integral y capaz de construir sus propios aprendizajes.

\section{Contextos para el aprendizaje en el nivel de sala cuna}

Los aportes teóricos y empíricos que evidencian la importancia de los seis primeros años de vida en el desarrollo posterior de un ser humano, tiene claras consecuencias para la labor que están desempeñando las educadoras de párvulos y, más específicamente para aquellas profesionales que atienden a niñas y niños que asisten al nivel de sala cuna, pues ya no es suficiente ofrecer una atención asistencial a las y los lactantes, sino que se requiere, además, proporcionar una atención pedagógica de calidad, donde se le ofrezcan a las y los menores experiencias educativas relevantes y pertinentes, lo que ha tenido implicancias directas para aquellas educadoras que se encuentran en ejercicio, pues, se han visto en la necesidad de tener que apropiarse de los fundamentos y principios que 
sustentan el currículum nacional para la educación parvularia, además de ser capaces de operacionalizarlo en el aula desde el nivel de sala cuna.

El currículum vigente para la Educación Parvularia, específicamente en Chile ${ }^{2}$, define diferentes contextos para el aprendizaje, donde se destaca la planificación curricular que debe diseñar la educadora de párvulos, pues no solo correspondería a "una de las actividades más profesionalizantes en el ámbito de enseñanza"(Montero, 2001:49), sino que se constituye en un aspecto fundamental dentro de todo el proceso de desarrollo curricular, porque coordina y explicita los principales propósitos de todos los agentes, factores o componentes del currículum (MINEDUC, 2001:89). Esta tarea se constituye en una actividad que ofrece a las y los educadores la posibilidad de relacionar los conocimientos teóricos con las situaciones reales del aula (Montero,2001:49), constituyéndose de este modo en una pieza clave para proyectar y plasmar la intencionalidades educativas que van a permitir darle sentido al proceso pedagógico (Díaz, 2010:63). En consecuencia, en la acción de planificar se ve reflejada la anticipación del conjunto de situaciones educativas que serán ofrecidas a los niños y niñas para potenciar sus aprendizajes y su desarrollo y, en este sentido, la educadora debe ser capaz de seleccionar, jerarquizar, secuenciar y graduar los aprendizajes esperados, al tiempo que debe ser capaz de definir y organizar los diversos factores que intervienen en el desarrollo del currículum tales como el tiempo, espacio, recursos, en otros. En concreto, se puede decir que la acción de planificar se constituye en una acción eminentemente deliberativa por cuanto todas las decisiones que tome una educadora al momento de planificar deben estar sustentadas sobre la base de determinados fundamentos y principios pedagógicos, pues, solo a partir de ello se podrá dar respuesta “al qué, para qué, cómo, cuándo, dónde, en cuánto tiempo se pretende enseñar” (Castro, Correa y Lira, 2005:90).

Además de lo anterior, y aunque parezca obvio, toda acción educativa se lleva a cabo en un tiempo y espacio determinado, por lo que ambos elementos deben ser

\footnotetext{
${ }^{2}$ A partir del 2001, en Chile se comienza a implementar la Reforma en Educación Parvularia expresada a través de las Bases Curriculares. Este marco curricular oficial tiene como propósito central favorecer el mejoramiento sustantivo de la educación de los niños y niñas menores de seis años. Define un cuerpo de objetivos que busca ampliar las posibilidades de aprendizaje considerando las características y potencialidades de niñas y niñas, los nuevos escenarios familiares y culturales del país y los avances de la pedagogía.
} 
altamente valorados y cuidadosamente organizados dentro del diseño de situaciones educativas que sean pertinentes, relevantes y potenciadoras. En este sentido, se puede decir que el espacio educativo se constituye en un eje dinamizador de múltiples posibilidades educativas y puede ser definido como "la conjunción de los aspectos físicos (la materialidad, la luz, el diseño, la ventilación, las dimensiones, entre otros) con los aspectos organizacionales, funcionales y estéticos (la distribución del equipamiento, la disposición de los materiales, etc.) propios del ambiente de aprendizaje" (MINEDUC, 2001:100). En cuanto a las características del espacio físico para la educación infantil, concordamos con Zabalza (1996), cuando señala que éste debe ser un espacio amplio, bien diferenciado, de fácil acceso y especializado, es decir, fácilmente identificable por los niños/as tanto desde el punto de vista de su función como de las actividades que se realizan en ellos (p.50). Por lo tanto, la selección, adaptación y organización de los espacios educativos, se presenta como otro recurso fundamental para promover aprendizajes en los niños y niñas.

En lo referido al tiempo de trabajo pedagógico, se puede decir que también es un elemento clave en la calidad de los procesos educativos (Díaz, 2010; MINEDUC, 2001). Este componente está en directa relación con la definición de los diferentes periodos de trabajo, sus características y la secuencia que éstos deben ocupar para responder a los propósitos formativos de los niños y niñas. Al respecto, es importante mencionar que dentro del currículum vigente para la Educación Parvularia chilena se establecen criterios generales que orientan sobre la organización del tiempo a corto plazo, entre ellos se pueden destacar los siguientes:

- La selección y duración de los periodos en función de las características, intereses, necesidades y fortalezas de los niños

- La renovación de la jornada de trabajo atendiendo a los cambios estacionales, los avances y cambios de necesidades de los niños en sus aprendizajes, respondiendo de esta forma al principio de significación de las Bases Curriculares.

- La importancia de que la jornada establezca periodos propuestos por los propios niños u otros miembros de la comunidad educativa (familia, comunidad) es un 
criterio que dice relación con los contextos culturales y el nivel de desarrollo de los niños y niñas (MINEDUC, 2001: 105-106).

Por otra parte, concordamos con Peralta (2005) cuando plantea que,

Es especialmente importante cuidar que todo periodo sea educativo, en especial aquellos denominados "regulares" que ocupan gran parte de la jornada de trabajo con niños de esa edad. Ello implica que desde la muda hasta los momentos de alimentación, deben ser propicios afectiva y cognitivamente, debiéndose desarrollar situaciones de exploración de objetos pertinentes o conversaciones relacionadas con lo que se está haciendo. Por otro lado, es fundamental, evitar periodos "sin actividades intencionadas" por parte del adulto, que podrían ocurrir entre los momentos de cambio (p.149).

En consecuencia, la forma en cómo se distribuya el tiempo en la jornada diaria y la intencionalidad pedagógica que una educadora le atribuya a cada uno de los periodos de la jornada educativa, son elementos centrales que van a influir directamente en los logros que obtengan los niños y niñas en sus aprendizajes y en su desarrollo (Peralta, 2004).

Finalmente, uno de los contextos para el aprendizaje de gran importancia, pero al mismo tiempo uno de los más complejos, corresponde a la evaluación. De hecho, intentar buscar una definición en la literatura para este concepto resulta una acción complicada, pues existen diversas definiciones y múltiples perspectivas que han intentado proporcionarle un significado. En esta misma línea Díaz (2010), sostiene que hoy en día el significado de evaluación posee una mayor amplitud, por cuanto no es una acción que solo se remite a la calificación, sino que es comprendida como un recurso para mejorar y tomar conciencia de los procesos y resultados educativos (p. 171).

Ahora bien, bajo la polisemia de conceptos sobre la evaluación, se puede visualizar la integración de dos dimensiones prácticas, la primera referida a un proceso que implica la recogida y registro de información (medición) y la otra dimensión asociada a un proceso de la valoración, entendiendo que ambas perspectivas deben articularse de tal manera que den sustento a la toma de decisiones en función del mejoramiento de los aprendizajes que van logrando los niños y niñas. Por consiguiente, 
la evaluación es concebida como un proceso permanente, sistemático y riguroso que permite obtener antecedentes relevantes respecto a los logros de aprendizaje de los niños y niñas en función de objetivos y/o metas establecidas, pero también debería proporcionar información sobre la enseñanza y todos los elementos que en ella confluyen, de tal manera de retroalimentar los procesos y propender hacia el mejoramiento en todas sus dimensiones. Si transferimos estas ideas sobre la evaluación específicamente al nivel de sala cuna, se puede apreciar una complejidad aún mayor, especialmente en la labor pedagógica que ejerce la Educadora de Párvulos porque le demanda mayores desafíos, por cuanto debe ser capaz de comprender los múltiples lenguajes que poseen los lactantes. Al respecto, Peralta (2005) nos advierte sobre lo siguiente,

se pone énfasis en la evaluación de los aprendizajes significativos, a través de un saber observar y escuchar mejor a los niños en sus situaciones de aprendizaje, lo que en función a los bebés es fundamental, ya que se hace necesario tener la capacidad de "leer" sus múltiples lenguajes que son fundamentalmente gestuales y preverbales (p.166).

Como se puede apreciar, la operacionalización de cada uno de los contextos para el aprendizaje dentro del trabajo directo con los niños y niñas requiere que la Educadora de Párvulos sea capaz de ejercer con propiedad su rol profesional, lo que implica que debe comprender los sentidos y significados que dan sustento a la Educación Parvularia, junto con diseñar e implementar situaciones de aprendizaje que permitan potenciar aprendizajes de calidad en los párvulos, además de generar estrategias de monitoreo permanente sobre los logros en los aprendizajes y la evaluación de todo el conjunto de factores que confluyen dentro de la acción educativa.

En virtud a lo anterior, sostenemos que el rol profesional que juega una Educadora de Párvulos que se desempeña en el nivel de sala cuna, tiene una relevancia que históricamente no la había tenido, por cuanto es ella quien tiene la responsabilidad de diseñar e implementar en el aula un currículum que permita dar respuesta a las necesidades de los lactantes y sus familias. En concreto, debe ser capaz de trasladar al aula los sentidos y significados que actualmente dan sustento a la educación en los 
primeros años de vida de los párvulos. Esta aseveración ha generado el interés por conocer el significado que le atribuyen las educadoras de párvulos que se desempeñan en el nivel de sala cuna a cada uno de los contextos para el aprendizaje explicitados en las Bases Curriculares y cómo los trasfieren a su práctica pedagógica. A partir de este propósito nos planteamos los siguientes objetivos:

- Describir las características que presentan las planificaciones que diseñan las Educadoras de Párvulos para el trabajo dentro del nivel sala cuna.

- Caracterizar el espacio educativo que utilizan permanentemente las educadoras de párvulos para la generación de experiencias de aprendizajes en el nivel sala cuna.

- Caracterizar las prácticas evaluativas que realizan las Educadoras de Párvulos en el nivel sala cuna.

- Identificar los criterios que utilizan las Educadoras de Párvulos para la distribución del tiempo asignado a los periodos permanentes y variables en el nivel sala cuna.

- Determinar el rol que asumen las Educadoras de Párvulos dentro de la conducción del proceso educativo y el clima de aula que general a partir de su interacción con los niños y niñas.

\section{Metodología}

\subsection{Tipo de investigación}

Para llevar a cabo esta investigación, se utilizó un enfoque cualitativo a partir de un diseño de estudio de casos múltiple, entendido éste como un proceso de indagación caracterizado por el examen sistemático y en profundidad de casos de un fenómeno, tales como entidades sociales o entidades educativas únicas (Bisquerra, 2014: 309), lo que permitió indagar en los significados que construyen y validan tres Educadoras de Párvulos que se desempeñan en el nivel sala cuna.

\subsection{Contexto de estudio}

El estudio se llevó a cabo en tres salas cuna, una de ellas ubicada en la comuna de Chillán Viejo y dos en la comuna de Chillán. Cabe destacar que las tres instituciones han 
sido reconocidas por la JUNJI y han otorgado la autorización para llevar a cabo el estudio. Las características de cada uno de los centros educativos son las siguientes:

- Una sala cuna y jardín infantil ubicado en la comuna de Chillán Viejo, de dependencia municipal pero con transferencia de fondos de JUNJI. Este establecimiento atiende a 136 niños y niñas desde los 84 días hasta los 4 años 11 meses de edad, distribuidos en los distintos niveles de la Educación Parvularia.

- Una sala cuna y jardín infantil particular, con reconocimiento de JUNJI. Este establecimiento atiende a niños y niñas desde los 84 días hasta los 5 años y se ubica en la comuna de Chillán, en un sector más bien céntrico.

- Una sala cuna y jardín infantil perteneciente a JUNJI. Este establecimiento recibe a niños y niñas a partir de los 84 días hasta los 4 años. Está ubicado en un sector aledaño a Chillán, caracterizado por altos índices de pobreza, delincuencia y cesantía.

\subsection{Participantes}

Con el objeto de obtener los significados necesarios para el desarrollo de la investigación se seleccionaron intencionalmente tres educadoras de párvulos, por lo tanto corresponde a una muestra no probabilística, intencionada. La selección de cada una de las participantes se realizó considerando los siguientes criterios:

- Educadoras de Párvulos que se desempeñen en el nivel sala cuna.

- Educadoras de Párvulos que se desempeñen en la comuna de Chillán y/o Chillán Viejo.

- Educadoras de Párvulos que utilicen las Bases Curriculares para la Educación Parvularia como guía y apoyo para su labor pedagógica.

- Educadoras de Párvulos que tengan a lo menos dos años de experiencia laboral.

- Una Educadora de Párvulos que lleve a cabo su labor pedagógica dentro de una sala cuna perteneciente a la Junta Nacional de Jardines Infantiles.

- Una Educadora de Párvulos que lleve a cabo su labor pedagógica dentro de una sala cuna de dependencia municipal. 
- Una Educadora de Párvulos que lleve a cabo su labor pedagógica dentro de una sala cuna de dependencia particular.

A partir de estos criterios se seleccionaron tres educadoras de párvulos, una educadora que ejercía su labor en una sala cuna perteneciente a JUNJI; otra que ejercía su labor en una sala cuna de dependencia municipal con transferencia de fondos y una educadora que ejercía su labor en una sala cuna particular reconocida por la JUNJI. Cada una de las profesionales seleccionadas se constituyó en un estudio de caso.

\subsection{Técnicas para la recolección de datos}

Para el desarrollo de la investigación se han considerado las siguientes tres etapas: Etapa Analítica- Etapa Exploratoria y Etapa Interpretativa, cuyo detalle se presenta en la Tabla 1.

Tabla 1. Detalle de técnicas de recolección de información

\begin{tabular}{l} 
Técnicas de recogida de información \\
\hline Analítica \\
- Análisis de contenido \\
- Categorías semánticas: cada uno de los contextos para el aprendizaje \\
explicitados en las Bases Curriculares para la Educación Parvularia- \\
MINEDUC, 2001).
\end{tabular}

Fuente: elaboración propia

\subsection{Técnicas de análisis de la información}

Para lograr captar los sentidos y significados que las educadoras construyen en torno a la implementación de cada uno de los contextos para el aprendizaje explicitados en las Bases Curriculares, se ha seguido un riguroso proceso de análisis de la información que ha contemplado las siguientes acciones: selección, categorización, comparación, validación e interpretación de la realidad estudiada (Bisquerra, 2014: 357). Para llevar a cabo este proceso se comenzó con la reducción de la información a partir de categorías semánticas, acción que implicó la división y simplificación del contenido en códigos (ver Figura 1). Cabe destacar que las categorías utilizadas para realizar los análisis responden 
a categorías teóricas de carácter especializadas e indicadores levantados a partir de las Bases Curriculares para la Educación Parvularia (MINEDUC, 2001), específicamente en lo referido a cada uno de los contextos para el aprendizaje.

Finalmente, podemos decir que en todo momento se resguardó el control de la calidad necesaria del estudio, empleando para ello un exhaustivo proceso de triangulación que contempló las siguientes acciones:

- Análisis de documentos:

- Bases Curriculares para la Educación Parvularia (MINEDUC, 2001).

- Triangulación entre técnicas de recolección de información.

- Contraste entre entrevistas realizadas a cada una de las Educadoras.

- Contraste entre observaciones realizadas por cada caso de estudio.

- Contraste entre discurso de cada educadora y su acción en el aula.

- Contraste entre lo evidenciado a nivel del análisis documental y las técnicas de recolección de información utilizadas.

- Contraste entre los resultados entre casos de estudio, en función de los referentes teóricos utilizados en la investigación.

Figura 1. Categorías y códigos empleados para los análisis

\begin{tabular}{|c|c|}
\hline Planificación & $\begin{array}{l}\text {-Concepto de planificación. } \\
\text { •Criterios de planificación. } \\
\text {-Temporalidad de la planificación. }\end{array}$ \\
\hline $\begin{array}{l}\text { Organización } \\
\text { del espacio }\end{array}$ & $\begin{array}{l}\text { - Condiciones físicas básicas. } \\
\text {-Implementación de material didáctico. } \\
\text {-Ambientación. }\end{array}$ \\
\hline $\begin{array}{l}\text { Organización } \\
\text { del tiempo }\end{array}$ & $\begin{array}{l}\text {-Tipos de periodos. } \\
\text {-Duración de los periodos. } \\
\text {-Intencionalidad de cada periodo. }\end{array}$ \\
\hline Evaluación & $\begin{array}{l}\text { - Concepto de evaluación. } \\
\text { - Sistematicidad de la evaluación. } \\
\text { - Criterios de evaluación. } \\
\text { - Instrumentos de evaluación. }\end{array}$ \\
\hline $\begin{array}{l}\text { Ambiente de } \\
\text { aula }\end{array}$ & $\begin{array}{l}\text { - Rol de la educadora de párvulos dentro del aula. } \\
\text { - Relación que establece el adulto con los párvulos. }\end{array}$ \\
\hline
\end{tabular}

Fuente: Elaboración propia. 


\section{Resultados}

A continuación se presentan los principales resultados obtenidos para cada una de las categorías semánticas definidas. Si bien es cierto, cada caso posee una riqueza única que solamente puede ser valorada en términos individuales, es posible llegar a establecer algunas convergencias y divergencias en cuanto a sus percepciones sobre cada uno los contextos para el aprendizaje dentro del nivel en el cual se desempeñan.

Ahora bien, los resultados se presentan en base a las categorías presentadas anteriormente y los resultados del análisis preliminar realizado al marco curricular vigente para la Educación Parvularia chilena, específicamente en lo que respecta a cada uno de los contextos para el aprendizaje allí definidos y los resultados evidenciados directamente en tres aulas de sala cuna, a partir del discurso y la acción de las Educadoras de Párvulos. Estos resultados se pueden visualizar en las Tablas 2, 3, 4, 5 y 6.

Tabla 2. Contraste entre Bases Curriculares y resultados evidenciados a nivel del aula: categoría planificación

\begin{tabular}{|c|c|c|c|c|}
\hline Indicadores & $\begin{array}{c}\text { Evidencia Bases } \\
\text { Curriculares }\end{array}$ & Educadora 1 & Educadora 2 & Educadora 3 \\
\hline $\begin{array}{l}\text { Concepto de } \\
\text { planificación }\end{array}$ & $\begin{array}{l}\text { Documento técnico que } \\
\text { implica la selección, } \\
\text { jerarquización, } \\
\text { ordenamiento en } \\
\text { secuencias } \\
\text { gradualidad de los } \\
\text { aprendizajes esperados, } \\
\text { Acción de definir y } \\
\text { organizar los diversos } \\
\text { factores que intervienen } \\
\text { en el proceso educativo. }\end{array}$ & 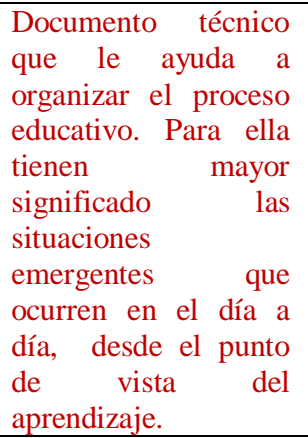 & $\begin{array}{lr}\text { Documento técnico } \\
\text { que le permite } \\
\text { organizar r el } \\
\text { conjunto r de } \\
\text { actividades que } \\
\text { serán ofrecidas a } \\
\text { los bebés en forma } \\
\text { semanal. }\end{array}$ & $\begin{array}{lr}\text { Documento } & \text { técnico } \\
\text { elaborado en } & \text { forma } \\
\text { colaborativa y } & \text { que } \\
\text { necesita } & \text { ser } \\
\text { complementado } & \text { con } \\
\text { un cronograma } & \text { semanal rara } \\
\text { favorecer } & \text { para } \\
\text { operacionalización en } \\
\text { el aula. }\end{array}$ \\
\hline $\begin{array}{l}\text { Criterios de } \\
\text { planificación }\end{array}$ & $\begin{array}{l}\text { - Contextualización } \\
\text { - Selección } \\
\text { graduación } \\
\text { - Sistematización } \\
\text { flexibilidad } \\
\text { - Integralidad } \\
\text { - Participación } \\
\end{array}$ & $\begin{array}{l}\text { - Contextualización y } \\
\text { diversificación }\end{array}$ & $\begin{array}{l}\text { - Contextualización } \\
\text { y } \\
\text { - Diversificación }\end{array}$ & $\begin{array}{ll}\text { - } & \text { Contextualización. } \\
\text { - Selección y } & \text { y } \\
& \text { graduación de los } \\
\text { aprendizajes. } & \\
\text { - Participación } \\
\text { - Flexibilidad. }\end{array}$ \\
\hline $\begin{array}{l}\text { Temporalidad } \\
\text { de la } \\
\text { planificación }\end{array}$ & $\begin{array}{l}\text { Flexibilidad en los } \\
\text { tiempos de duración de } \\
\text { las planificaciones, } \\
\text { puede ser a largo, } \\
\text { mediano y corto plazo. } \\
\text { Temporalidad de las } \\
\text { planificaciones a corto } \\
\text { plazo debe ser flexible } \\
\text { para el Primer Ciclo. }\end{array}$ & $\begin{array}{l}\text { Planificación diaria } \\
\text { complementa } \\
\text { actividades } \\
\text { programadas en } \\
\text { cronograma semanal, } \\
\text { Énfasis } \\
\text { planificaciones } \\
\text { parciales. } \\
\begin{array}{l}\text { Planificación es de } \\
\text { responsabilidad de } \\
\text { alumna en práctica. }\end{array} \\
\end{array}$ & $\begin{array}{lr}\text { Énfasis en } & \text { la } \\
\text { planificación } & \text { a } \\
\text { corto plazo. Se } \\
\text { diseña } & \text { un } \\
\text { cronograma cada } \\
\text { dos semanas. } \\
\text { Flexibilidad re } \\
\text { acuerdo a los logros } \\
\text { alcanzados por los } \\
\text { bebés. }\end{array}$ & $\begin{array}{l}\text { Planificación } \quad \begin{array}{l}\text { de } \\
\text { proyecto }\end{array} \\
\text { aprendizaje } \\
\text { comprende } 3 \text { meses. } \\
\text { Se complementa con } \\
\text { un cronograma } \\
\text { semanal. } \\
\text { Flexibilidad en las } \\
\text { experiencias ofrecidas } \\
\text { a los lactantes. }\end{array}$ \\
\hline
\end{tabular}




\begin{tabular}{|c|c|c|c|c|}
\hline $\begin{array}{l}\text { Formato de } \\
\text { planificación }\end{array}$ & $\begin{array}{lr}\text { Flexibilidad en función } \\
\text { de los énfasis de los } \\
\text { programas } \\
\text { modalidades. }\end{array}$ & $\begin{array}{l}\text { Cronograma } \\
\text { semanal que } \\
\text { incorpora para cada } \\
\text { día el enunciado de } \\
\text { las experiencias de } \\
\text { aprendizaje por } \\
\text { cada uno de los } \\
\text { núcleos. }\end{array}$ & $\begin{array}{lr}\text { La planificación se } \\
\text { reduce a un } \\
\text { cronograma simple } \\
\text { donde sólo se } \\
\text { incorpora el número } \\
\text { de aprendizaje } \\
\text { esperado } \\
\text { seleccionado y } & \text { el } \\
\text { nombre de } & \text { la } \\
\text { experiencia } & \text { de } \\
\text { aprendizaje, } & \text { no } \\
\text { incorpora } & \\
\text { orientaciones } & \\
\text { didácticas y los } \\
\text { procedimientos } \\
\text { evaluativos. }\end{array}$ & $\begin{array}{l}\text { El cronograma sólo } \\
\text { enuncia el nombre de } \\
\text { las experiencias de } \\
\text { aprendizaje, pero } \\
\text { describe claramente el } \\
\text { qué tiene que hacer y } \\
\text { decir el adulto cuando } \\
\text { está en contacto } \\
\text { directo con el lactante } \\
\text { y cómo debe hacerlo. }\end{array}$ \\
\hline
\end{tabular}

Tabla 2. Contraste entre Bases Curriculares y resultados evidenciados a nivel del aula: categoría planificación (continuación)

\begin{tabular}{|c|c|c|c|c|}
\hline Indicadores & $\begin{array}{c}\text { Evidencia Bases } \\
\text { Curriculares }\end{array}$ & Educadora 1 & Educadora 2 & Educadora 3 \\
\hline $\begin{array}{l}\text { Significado de } \\
\text { la planificación }\end{array}$ & $\begin{array}{l}\text { Aspecto fundamental } \\
\text { dentro de todo proceso } \\
\text { de desarrollo curricular, } \\
\text { ya que coordina y } \\
\text { explicita los principales } \\
\text { propósitos de todos los } \\
\text { agentes, factores o } \\
\text { componentes del } \\
\text { currículum. }\end{array}$ & $\begin{array}{l}\text { Sólo corresponde a } \\
\text { un documento } \\
\text { técnico que debe ser } \\
\text { diseñado como } \\
\text { exigencia de la } \\
\text { práctica. } \\
\text { situaciones } \\
\text { emergentes tienen } \\
\text { mayor significado. }\end{array}$ & $\begin{array}{l}\text { El cronograma tiene } \\
\text { mayor significado, } \\
\text { porque permite } \\
\text { ordenar } \\
\text { actividades } \\
\text { forma semanal. }\end{array}$ & $\begin{array}{l}\text { El cronograma tiene } \\
\text { mayor significado en } \\
\text { la práctica, permite } \\
\text { organizar las } \\
\text { experiencias de } \\
\text { aprendizaje en forma } \\
\text { semanal y orienta a } \\
\text { las asistentes en } \\
\text { cuanto a su acción } \\
\text { frente a los lactantes. }\end{array}$ \\
\hline
\end{tabular}

Fuente: Elaboración propia

Tabla 3. Contraste entre Bases Curriculares y resultados evidenciados a nivel del aula: categoría organización del espacio

\begin{tabular}{|c|c|c|c|c|}
\hline Indicadores & $\begin{array}{c}\text { Evidencia Bases } \\
\text { Curriculares }\end{array}$ & Educadora 1 & Educadora 2 & Educadora 3 \\
\hline $\begin{array}{l}\text { Condiciones } \\
\text { físicas básicas }\end{array}$ & $\begin{array}{l}\text { El espacio debe } \\
\text { proveer las } \\
\text { condiciones físicas } \\
\text { básicas que garanticen } \\
\text { la integración, la } \\
\text { seguridad, el bienestar } \\
\text { y la exploración } \\
\text { confiada de los niños } \\
\text { y niñas. }\end{array}$ & $\begin{array}{l}\text { Sala nueva, } \\
\text { construida } \\
\text { específicamente para } \\
\text { el nivel de Sala } \\
\text { cuna, por lo que } \\
\text { cumple con los } \\
\text { requerimientos } \\
\text { básicos de seguridad } \\
\text { y bienestar. }\end{array}$ & $\begin{array}{l}\text { El espacio físico de } \\
\text { la sala es amplio } \\
\text { y cumple con } \\
\text { medidas de } \\
\text { seguridad para los } \\
\text { bebés. }\end{array}$ & $\begin{array}{l}\text { Condiciones físicas } \\
\text { básicas y de } \\
\text { seguridad para los } \\
\text { lactantes. }\end{array}$ \\
\hline $\begin{array}{l}\text { Implementación } \\
\text { de material } \\
\text { didáctico }\end{array}$ & $\begin{array}{l}\text { Variados, } \\
\text { cuidadosamente } \\
\text { seleccionados de } \\
\text { acuerdo a las } \\
\text { posibilidades reales } \\
\text { para el logro de los } \\
\text { aprendizajes } \\
\text { esperados. } \\
\text { El material debe } \\
\text { responder a las } \\
\text { características, } \\
\text { necesidades e intereses } \\
\text { de los niños y niñas y } \\
\text { favorecer la autonomía } \\
\text { en el aprendizaje. }\end{array}$ & $\begin{array}{l}\text { Material didáctico } \\
\text { implementado sólo } \\
\text { como un recurso de } \\
\text { entretención, sin } \\
\text { intencionalidad } \\
\text { pedagógica. } \\
\text { material se mantiene } \\
\text { en el tiempo. }\end{array}$ & $\begin{array}{lr}\text { Escaso } & \text { material } \\
\text { didáctico dentro del } \\
\text { aula. } \\
\text { Recursos } & \\
\text { necesarios } & \text { para } \\
\text { apoyar } & \text { las } \\
\text { experiencias } & \text { de } \\
\text { aprendizaje } & \text { son } \\
\text { trasladados al aula } \\
\text { sólo cuando } & \text { se } \\
\text { requieren. } & \end{array}$ & 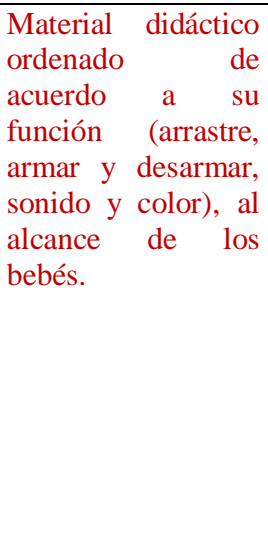 \\
\hline
\end{tabular}




\begin{tabular}{|c|c|c|c|c|}
\hline Ambientación & $\begin{array}{l}\text { La ambientación } \\
\text { aula juega un rol } \\
\text { fundamental en } \\
\text { bienestar de los niños y } \\
\text { niñas y en la } \\
\text { potenciación de los } \\
\text { aprendizajes. Debe ser } \\
\text { cuidadosamente } \\
\text { intencionada y debe } \\
\text { cumplir con el criterio } \\
\text { de pertinencia cultural. }\end{array}$ & $\begin{array}{l}\text { Decoración } \\
\text { elaborada por el } \\
\text { adulto (asistente), la } \\
\text { sala está decorada } \\
\text { con figuras variadas, } \\
\text { sin sentido } \\
\text { pedagógico. }\end{array}$ & $\begin{array}{l}\text { Decoración } \\
\text { confeccionada por } \\
\text { el adulto, sin un } \\
\text { sentido pedagógico } \\
\text { definido. }\end{array}$ & $\begin{array}{l}\text { Solamente se } \\
\text { observan móviles } \\
\text { que cuelgan desde el } \\
\text { techo de la sala } \\
\text { cuya función es la } \\
\text { de entretener visual y } \\
\text { auditivamente a los } \\
\text { lactantes. }\end{array}$ \\
\hline
\end{tabular}

Fuente: Elaboración propia

Tabla 4. Contraste entre Bases Curriculares y resultados evidenciados a nivel del aula: categoría organización del tiempo

\begin{tabular}{|c|c|c|c|c|}
\hline Indicadores & $\begin{array}{c}\text { Evidencia Bases } \\
\text { Curriculares }\end{array}$ & Educadora 1 & Educadora 2 & Educadora 3 \\
\hline $\begin{array}{l}\text { Tipos de } \\
\text { periodos }\end{array}$ & \begin{tabular}{llr} 
Dentro de & la \\
organización & del \\
trabajo diario, los tipos \\
de & \multicolumn{2}{c}{ periodos } \\
corresponden & a & los \\
permanentes & & o \\
constantes & y & los \\
variables. & & \\
\end{tabular} & $\begin{array}{l}\text { En la distribución } \\
\text { de la jornada diaria } \\
\text { se incorporan } \\
\text { periodos } \\
\text { permanentes y } \\
\text { actividades } \\
\text { variables, }\end{array}$ & $\begin{array}{l}\text { En la distribución de } \\
\text { la jornada diaria se } \\
\text { incorporan periodos } \\
\text { permanentes y } \\
\text { periodos designados } \\
\text { como actividades } \\
\text { variables. }\end{array}$ & $\begin{array}{l}\text { La jornada diaria se } \\
\text { distribuye a través } \\
\text { de periodos } \\
\text { permanentes y dos } \\
\text { periodos variables, } \\
\text { uno denominado } \\
\text { "Contextos de } \\
\text { exploración" en la } \\
\text { mañana y un } \\
\text { periodo } \\
\text { denominado } \\
\text { "Actividad de } \\
\text { estimulación". }\end{array}$ \\
\hline $\begin{array}{c}\text { Duración de los } \\
\text { periodos }\end{array}$ & $\begin{array}{l}\text { La duración de cada } \\
\text { uno de los periodos es } \\
\text { relativa, depende de las } \\
\text { características de los } \\
\text { niños y niñas, del su } \\
\text { nivel de desarrollo, de } \\
\text { los aprendizajes } \\
\text { seleccionados. } \\
\text { Dentro de la } \\
\text { distribución de le den } \\
\text { jornada diaria se deben } \\
\text { incorporar periodos } \\
\text { permanentes y periodos } \\
\text { variables en forma } \\
\text { equilibrada. }\end{array}$ & $\begin{array}{l}\text { La duración es } \\
\text { variable, depende } \\
\text { de cada periodo. } \\
\text { Periodos } \\
\text { permanentes } \\
\text { abarcan casi la } \\
\text { totalidad del } \\
\text { tiempo establecido } \\
\text { para la jornada } \\
\text { diaria, por lo que el } \\
\text { tiempo de los } \\
\text { periodos variables } \\
\text { es muy reducido. }\end{array}$ & $\begin{array}{l}\text { La duración es } \\
\text { variable, depende de } \\
\text { cada periodo. } \\
\text { Periodos } \\
\text { permanentes } \\
\text { abarcan casi la } \\
\text { totalidad del tiempo } \\
\text { establecido para la } \\
\text { jornada diaria (9 } \\
\text { horas cronológicas), } \\
\text { por lo que el tiempo } \\
\text { de los periodos } \\
\text { variables se reduce a } \\
2 \text { horas cronológicas. }\end{array}$ & $\begin{array}{l}\text { Periodos } \\
\text { permanentes ocupan } \\
\text { gran parte de la } \\
\text { jornada diaria. (7 } \\
\text { horas Se establece } \\
\text { un periodo variable } \\
\text { en la mañana } \\
\text { (contexto de } \\
\text { exploración) con una } \\
\text { duración aproximada } \\
\text { de } 30 \text { minutos y un } \\
\text { periodo variable en } \\
\text { la jornada de la tarde } \\
\text { (actividad de } \\
\text { estimulación) con } \\
\text { una duración } \\
\text { aproximada de } 20 \\
\text { minutos. }\end{array}$ \\
\hline $\begin{array}{c}\text { Intencionalidad } \\
\text { de cada } \\
\text { periodo }\end{array}$ & $\begin{array}{l}\text { Cada momento de la } \\
\text { jornada debe favorecer } \\
\text { el logro de cierto tipo } \\
\text { de aprendizaje } \\
\text { esperado, por lo que } \\
\text { tanto los periodos } \\
\text { permanentes como los } \\
\text { variables deben ser } \\
\text { planificados. }\end{array}$ & $\begin{array}{l}\text { Diseño de un plan de } \\
\text { rutina, pero sin } \\
\text { vinculación directa de } \\
\text { cada uno de los } \\
\text { periodos permanentes } \\
\text { con algún aprendizaje } \\
\text { esperado. }\end{array}$ & $\begin{array}{l}\text { Se seleccionan } \\
\text { aprendizajes } \\
\text { esperados } \\
\text { posibles } \\
\text { actividades } \\
\text { inicio del al año } \\
\text { escolar, pero no } \\
\text { hay vinculación } \\
\text { directa de cada } \\
\text { uno de los periodos } \\
\text { permanentes } \\
\text { variables y } \\
\text { algún aprendizaje } \\
\text { esperado. }\end{array}$ & $\begin{array}{l}\text { Intencionalidad } \\
\text { pedagógica de cada } \\
\text { periodo se establece } \\
\text { dentro del } \\
\text { cronograma, } \\
\text { algunos periodos } \\
\text { están vinculados a } \\
\text { algún aprendizaje } \\
\text { esperado. }\end{array}$ \\
\hline
\end{tabular}




\begin{tabular}{|c|c|c|c|c|}
\hline $\begin{array}{l}\text { Evaluación de } \\
\text { cada periodo }\end{array}$ & $\begin{array}{l}\text { La renovación de la } \\
\text { jornada de trabajo y la } \\
\text { duración de los } \\
\text { periodos } \\
\text { planificarse atendiendo } \\
\text { los cambios } \\
\text { estacionales, los } \\
\text { avances y cambio de } \\
\text { necesidades de los } \\
\text { niños en sus } \\
\text { aprendizajes, tiempos } \\
\text { de concentración y de } \\
\text { realización de las } \\
\text { actividades. }\end{array}$ & $\begin{array}{l}\text { Evaluación sobre la } \\
\text { efectividad del tiempo } \\
\text { dentro de la jornada } \\
\text { diaria es evaluada de } \\
\text { manera informal, sin } \\
\text { modificaciones en el } \\
\text { caso de ser necesario. } \\
\text { Permanece invariante } \\
\text { a lo largo del año. }\end{array}$ & $\begin{array}{l}\text { No hay evaluación } \\
\text { de la efectividad de } \\
\text { los tiempos } \\
\text { asignados en la } \\
\text { distribución de la } \\
\text { jornada diaria. } \\
\text { Permanece } \\
\text { invariante durante } \\
\text { todo el año. }\end{array}$ & $\begin{array}{lrr}\text { Una vez } & \text { a } & \text { la } \\
\text { semana se evalúa la } \\
\text { efectividad } & \text { del } \\
\text { tiempo, pero } & \text { los } \\
\text { periodos } & \text { de } & \text { la } \\
\text { jornada } & \text { diaria } \\
\text { permanece } & & \\
\text { invariante lo largo } \\
\text { del año. }\end{array}$ \\
\hline
\end{tabular}

Fuente: Elaboración propia

Tabla 5. Contraste entre Bases Curriculares y resultados evidenciados a nivel del aula: categoría evaluación

\begin{tabular}{|c|c|c|c|c|}
\hline Indicadores & $\begin{array}{c}\text { Evidencia Bases } \\
\text { Curriculares }\end{array}$ & Educadora 1 & Educadora 2 & Educadora 3 \\
\hline $\begin{array}{l}\text { Concepto de } \\
\text { evaluación }\end{array}$ & $\begin{array}{l}\text { Acción } \\
\text { planificada, } \\
\text { permanente } \\
\text { sistemática, } \\
\text { progresiva } \\
\text { pertinente. } \\
\text { Base para toma de } \\
\text { decisiones. } \\
\begin{array}{ll}\text { Focalizada en el } \\
\text { niño y en la } \\
\text { efectividad de la } \\
\text { enseñanza. }\end{array}\end{array}$ & $\begin{array}{lr}\text { Evaluación } & \text { como } \\
\text { medición de los } \\
\text { aprendizajes. }\end{array}$ & $\begin{array}{llr}\text { Evaluación } & & \text { como } \\
\text { medición de } & \text { los } \\
\text { niveles de } & \text { logro } \\
\text { alcanzados por } & \text { los } \\
\text { lactantes en función } \\
\text { de los aprendizajes } \\
\text { esperados. }\end{array}$ & $\begin{array}{l}\text { Evaluación } r \text { como } \\
\text { medición de los } \\
\text { niveles de logro } \\
\text { alcanzados por los } \\
\text { lactantes en función } \\
\text { de los aprendizajes } \\
\text { esperados. } \\
\text { comparan resultados } \\
\text { individuales a lo } \\
\text { largo del tiempo. Se } \\
\text { complementa con la } \\
\text { información } \\
\text { recolectada por la } \\
\text { educadora } \\
\text { entrevista con las } \\
\text { familias. }\end{array}$ \\
\hline $\begin{array}{c}\text { Sistematicidad } \\
\text { de la } \\
\text { evaluación }\end{array}$ & $\begin{array}{l}\text { Aplicación de una } \\
\text { evaluación al inicio } \\
\text { con carácter de } \\
\text { diagnóstico, } \\
\text { evaluación durante } \\
\text { el proceso con } \\
\text { carácter formativo } \\
\text { y evaluación al } \\
\text { término del } \\
\text { periodo con } \\
\text { carácter sumativa. }\end{array}$ & $\begin{array}{l}\text { Aplicación de pauta } \\
\text { de diagnóstico al } \\
\text { inicio del proceso, } \\
\text { evaluación } \\
\text { cohorte aplicada en } \\
\text { julio y evaluación } \\
\text { final aplicada al } \\
\text { término del año } \\
\text { escolar, como } \\
\text { exigencia de la } \\
\text { institución. }\end{array}$ & $\begin{array}{l}\text { No hay evaluación en } \\
\text { forma sistemática. }\end{array}$ & $\begin{array}{l}\text { La sistematicidad de } \\
\text { la evaluación se ve } \\
\text { interferida por } \\
\text { labores } \\
\text { administrativas } \\
\text { exigidas por la } \\
\text { institución. }\end{array}$ \\
\hline $\begin{array}{l}\text { Criterios de } \\
\text { evaluación }\end{array}$ & $\begin{array}{l}\text { Orientaciones } \\
\text { generales respecto } \\
\text { a la evaluación } \\
\text { criterial, } \\
\text { valoriza } \\
\text { mayormente la } \\
\text { evaluación } \\
\text { psicométrica. }\end{array}$ & \begin{tabular}{lr} 
Instrumentos & de \\
evaluación & \\
seleccionados & de \\
acuerdo a la edad. \\
\multicolumn{2}{l}{ Indicadores } \\
evaluación de \\
formulan de acuerdo \\
a la edad, los \\
aprendizajes \\
seleccionados \\
experiencias \\
aprendizaje.
\end{tabular} & $\begin{array}{lr}\text { Cuando } & \text { se } \\
\text { seleccionan } & \\
\text { instrumentos } & \text { de } \\
\text { evaluación } & \text { se } \\
\text { utilizan los criterios } \\
\text { de flexibilidad, } \\
\text { factibilidad, } \\
\text { facilidad en la } \\
\text { aplicación } \\
\begin{array}{l}\text { confiabilidad, pero } \\
\text { no se hace con } \\
\text { regularidad. }\end{array}\end{array}$ & $\begin{array}{l}\text { El diagnóstico es el } \\
\text { principal criterio. } \\
\text { La edad de cada } \\
\text { lactante } \\
\text { asistencia. }\end{array}$ \\
\hline
\end{tabular}




\begin{tabular}{|c|c|c|c|c|}
\hline $\begin{array}{l}\text { Instrumentos } \\
\text { de evaluación }\end{array}$ & $\begin{array}{l}\text { Sólo se aluden } \\
\text { instrumentos en } \\
\text { función de la } \\
\text { evaluación de los } \\
\text { aprendizajes de los } \\
\text { niños y niñas, entre } \\
\text { ellos: Escala de } \\
\text { apreciación- } \\
\text { Registro anecdótico } \\
\text { - Lista de Cotejo - } \\
\text { Informes al hogar - } \\
\text { Entrevistas a la } \\
\text { familia. }\end{array}$ & $\begin{array}{l}\text { Énfasis en la } \\
\text { utilización de la lista } \\
\text { de cotejo. } \\
\text { No hay presencia de } \\
\text { instrumentos de } \\
\text { evaluación dentro } \\
\text { del aula. }\end{array}$ & $\begin{array}{l}\text { Escala de } \\
\text { apreciación, pero } \\
\text { no hay presencia de } \\
\text { ésta en el aula. }\end{array}$ & $\begin{array}{l}\text { Pauta edumétrica } \\
\text { institucional diseñada } \\
\text { por equipo de } \\
\text { educadoras. } \\
\text { Lista de cotejo y } \\
\text { escala de apreciación } \\
\text { para la evaluación de } \\
\text { proceso. } \\
\text { Bitácora que recoge } \\
\text { información } \\
\text { cualitativa. }\end{array}$ \\
\hline
\end{tabular}

Fuente: Elaboración propia

Tabla 6. Contraste entre Bases Curriculares y resultados evidenciados a nivel del aula: categoría clima de aula

\begin{tabular}{|c|c|c|c|c|}
\hline Indicadores & $\begin{array}{c}\text { Evidencia Bases } \\
\text { Curriculares }\end{array}$ & Educadora 1 & Educadora 2 & Educadora 3 \\
\hline $\begin{array}{c}\text { Rol de la } \\
\text { educadora de } \\
\text { párvulos } \\
\text { dentro del } \\
\text { aula }\end{array}$ & $\begin{array}{l}\text { Liderar el proceso de } \\
\text { enseñanza-aprendizaje, } \\
\text { planificando, } \\
\text { implementando } \\
\text { evaluando el trabajo } \\
\text { educativo en todos sus } \\
\text { aspectos. }\end{array}$ & $\begin{array}{l}\text { Alumna en práctica } \\
\text { asume un rol activo } \\
\text { dentro del aula, apoyada } \\
\text { por las asistentes. } \\
\text { Educadora asume un rol } \\
\text { pasivo, colaborando sólo } \\
\text { en algunas situaciones } \\
\text { que lo requiere. }\end{array}$ & $\begin{array}{l}\text { Asistente cumple un } \\
\text { rol activo dentro de la } \\
\text { conducción de las } \\
\text { experiencias de } \\
\text { aprendizaje. } \\
\text { A nivel de adultos se } \\
\text { observa } \\
\text { descoordinación y } \\
\text { conflictos de poder } \\
\text { entre la educadora y } \\
\text { una de las asistentes. }\end{array}$ & $\begin{array}{l}\text { Rol activo en la } \\
\text { conducción de } \\
\text { algunas experiencias } \\
\text { de aprendizaje o } \\
\text { actividades propias de } \\
\text { cada periodo. } \\
\text { Rol activo de las } \\
\text { asistentes en forma } \\
\text { permanente, con } \\
\text { énfasis en el periodo } \\
\text { de las mudas. }\end{array}$ \\
\hline
\end{tabular}

Fuente: elaboración propia

\section{Discusión y conclusiones}

Hoy en día resulta necesario observar detenidamente lo que sucede dentro de las aulas que atienden a niños y niñas menores de dos años, pues, por una parte los avances científicos y teóricos emanados desde las neurociencias evidencian la importancia de una 
estimulación oportuna y pertinente en los 3 primeros años de vida de una persona, por otro lado, a nivel país se han invertido una gran cantidad de recursos económicos y humanos en este nivel de la Educación Parvularia, lo que ha favorecido un aumento en la cobertura de atención para niños y niñas menores de dos años, pero dicha estrategia no necesariamente podría estar asociada con la calidad de la atención que se les está proporcionando a los menores, donde la responsabilidad de este último aspecto recae principalmente en las educadoras y en la comunidad educativa en general. Por lo tanto, el conocimiento que posea una educadora sobre los aportes de las neurociencias y el significado que le atribuya al marco curricular orientador para el nivel, específicamente en lo que respecta a la operacionalización de los diferentes contextos para el aprendizaje, podría tener un impacto directo en la potenciación del aprendizaje y desarrollo de los párvulos.

Las Bases Curriculares para la Educación Parvularia en Chile explicitan claramente la necesidad de que dentro del proceso educativo de los párvulos se consideren de manera integrada cada uno de los contextos para el aprendizaje, vale decir, la planificación, la conformación de comunidades de aprendizaje, la organización del tiempo, la organización del espacio y la evaluación (MINEDUC, 2001).

En base a lo anterior, se puede decir que en este estudio se evidencia que el concepto de planificación manejado por las tres educadoras hace referencia a planificaciones mínimas, es decir, aquellas que se diseñan a corto plazos. Además, estructuralmente estas planificaciones adoptan un formato que responde a un cronograma semanal simple, lo que permite inferir que el diseño de este documento técnico tiene sentido solamente en la medida en que permita organizar las experiencias de aprendizaje para un determinado tiempo, donde se detallan de manera muy específica las orientaciones didácticas para guiar a las asistentes de párvulos, no sucediendo lo mismo con la intencionalidad pedagógica.

Por otro lado, se observa que estas profesionales tienen un escaso conocimiento sobre la denominación de los criterios generales que se establecen dentro de las Bases Curriculares respecto a la planificación, pues sólo una de ellas señaló en forma explícita que diseñaba sus planificaciones teniendo en consideración el criterio de diversificación. Cabe destacar que todas consideran el diagnóstico y la edad de los párvulos como uno de 
los criterios para el diseño de sus planificaciones, ya que para ellas se constituyen en referentes importantes que les permiten programar el trabajo con los párvulos, lo que en alguna medida estaría en directa relación con el criterio de contextualización (MINEDUC, 2001). No obstante, se puede decir que los criterios que utilizan para seleccionar y diseñar sus planificaciones responden a aspectos vinculados directamente con su práctica y a denominaciones que ellas han ido estableciendo a lo largo de su experiencia profesional.

En lo que respecta a la distribución del tiempo, se observa que las tres educadoras no valoran la organización de este elemento curricular como un factor que puede condicionar la adquisición de aprendizajes en los párvulos. Si bien es cierto sus jornadas diarias de atención a los niños y niñas están distribuidas a través de periodos permanentes y variables, solamente estos últimos adquieren, en alguna medida, una intencionalidad pedagógica a través de los cronogramas que diseñan. Esta situación induce a cuestionar el sentido pedagógico que poseen estos niveles de sala cuna en particular, debido a que la mayor parte del tiempo diario se focaliza en la formación de hábitos, la satisfacción de las necesidades y cuidados básicos de los bebés y, solo en algunas oportunidades se les ofrecen situaciones de aprendizaje de acuerdo a las necesidades que presenta cada párvulo, las que mayoritariamente están a cargo de las asistentes, pues la educadora frecuentemente no se encuentra presente en el aula.

En lo que respecta a la caracterización del espacio educativo donde llevan a cabo su acción pedagógica estas tres educadoras de párvulos se preocupan que este contexto para el aprendizaje cumpla con ofrecer seguridad y bienestar para los bebés, pero la dotación de material didáctico y la ambientación del aula solamente cumple con una función instrumental, cuya finalidad es la de entretener a los lactantes en determinados momentos y de ornamentar la sala, por lo que espacio educativo tampoco ha sido cuidadosamente estructurado e intencionado, por lo que no cumple a cabalidad con ofrecer oportunidades de aprendizaje que favorezcan la exploración confiada, el juego y la autonomía en el aprendizaje, a pesar de que se ha demostrado que el ambiente físico y cultural donde se desenvuelve el niño o niña es fundamental en el proceso educativo, pues tiene importantes repercusiones en su desarrollo posterior (Bravo y Morales, 2012; López, 2013), información que debería ser conocida por las educadoras. 
Uno de los aspectos que genera mayores dificultades dentro de la labor que desempeñan estas educadoras, corresponde a la evaluación. Al respecto, se observan dificultades referidas al diseño de instrumentos propios a partir del levantamiento de indicadores que respondan efectivamente a la evaluación de los aprendizajes esperados que han seleccionado y que les permitan llegar a establecer los niveles de logro alcanzados por los párvulos, por lo que se focalizan en la utilización de pautas edumétricas que son proporcionadas por la institución con la finalidad de aplicarlas para llevar a cabo el diagnóstico al inicio del proceso, una evaluación de corte y una evaluación sumativa que ayude a determinar los resultados que cada niño/a ha logrado.

Lo anterior, permite sostener que al visualizarse cierto grado de complejidad en el proceso evaluativo, estas educadoras prefieren optar por el camino más simple utilizando principalmente pautas de evaluación que ya han sido validadas formalmente, pero a nuestro juicio la situación más seria que se presenta en la evaluación es que estas educadoras no están evaluando en forma sistemática, pues no fue posible evidenciar registros de evaluación en el aula, por lo que los juicios de valor y las tomas de decisiones se formulan a partir de percepciones subjetivas que ellas poseen sobre los logros de los niños y no sobre información recogida a través de un proceso riguroso, lo que en alguna medida podría invalidar la información que se transmite, principalmente a las familias. Por otra parte, se observa una concepción tradicional de la evaluación, por cuanto estas educadoras vinculan la evaluación a la acción de medir solo los aprendizajes de los niños y niñas, dejando de lado la evaluación de todos aquellos aspectos y elementos que influyen directamente dentro del desarrollo del proceso educativo (Bravo y Morales, 2012).

En cuanto a la categoría referida al clima que genera la educadora en el aula, se puede observar que estas tres educadoras lamentablemente delegan en forma muy frecuente la responsabilidad de conducir las experiencias de aprendizajes o situaciones de estimulación a las asistentes que están en el aula, por lo que son estas últimas quienes asumen un rol activo en la conducción de experiencias de aprendizaje, en la generación de un clima de afecto y seguridad, y en la satisfacción de las necesidades básicas de los bebés. A nuestro juicio, esta situación se presenta debido a que las educadoras asumen dentro del establecimiento, además, diversas funciones de carácter administrativo, condición que las llevan a tener que ausentarse del aula en forma reiterativa. Esta 
situación, a nuestro juicio se transforma en un nudo crítico en lo que respecta a las oportunidades que se les ofrecen a los párvulos para favorecer en ellos aprendizajes que sean significativos, relevantes y pertinentes, pues, el hecho de que coincidentemente en las tres realidades estudiadas se delegaba dicha acción a las asistentes conlleva, una vez más en este estudio, a cuestionar la función pedagógica que se busca instalar en este nivel educativo, porque a pesar de que la educadora es la especialista en atención de niños y niñas, y es ella quien intenciona la acción educativa por medio de la planificación, el hecho de no estar presente en el aula le impide monitorear y/o supervisar la forma en como las técnicos están ejecutando la planificación e interactuando con los lactantes en cada uno de los periodos permanentes y variables, para favorecer sus aprendizajes.

Además de lo anterior, a partir de los resultados de este estudio, se concluye que el significado que las educadoras le atribuyen a la operacionalización en el aula de cada uno de los contextos para el aprendizaje que se explicitan en las Bases Curriculares, tiene un alcance vinculado más a las apreciaciones, creencias e interpretaciones realizadas por ellas a lo largo de su experiencia, lo que permite afirmar que estas profesionales tienen un conocimiento muy parcial de los fundamentos, principios pedagógicos $\mathrm{y}$, especialmente, en los aspectos de fondo vinculados a cada uno de los contextos para el aprendizaje establecidos en el marco curricular, no ocurriendo lo mismo con los aprendizajes esperados que se agrupan en los núcleos de aprendizaje, pues estos se constituyen prácticamente en los únicos elementos curriculares que son considerados por las profesionales dentro de su acción práctica, es decir, en términos de su implementación en el aula.

Finalmente, concluimos que el rol profesional que estas educadoras de párvulos están asumiendo, en gran parte, no responde a los postulados y lineamientos que promueven las Bases Curriculares (MINEDUC, 2011). Por lo tanto, concordamos con Bravo y Morales (2012), cuando advierten sobre la necesidad de debatir políticas de formación inicial y permanente que contribuyan a la especialización de educadoras de párvulos para la atención de niños y niñas menores de 3 años, pues tenemos la firme convicción de que una educadora que se desempeñe en el nivel de sala cuna no solo debe estar capacitada en el ámbito curricular, didáctico y evaluativo, sino que también debe poseer una sensibilidad especial para trabajar con lactantes y las competencias 
necesarias para asumir con propiedad su rol profesional dentro de la conducción de los procesos educativos de los menores, pues es una etapa muy delicada del ser humano en lo que respecta al desarrollo de sus capacidades cognitivas, emocionales y motoras, y solo una profesional idónea para desempeñarse en este nivel podrá efectivamente ofrecer situaciones de aprendizaje que sean oportunas, relevantes y pertinentes para los lactantes, de acuerdo a sus posibilidades y a las características del contexto en el cual se desenvuelven.

\section{Referencias bibliográficas}

Aguilar, R. y Tansani, R. (2012). Joint analysis of preschool attendance and school performance in the short and longrun. International Journal of Educational Development, 32, 224-231.

Banco Mundial.(2011). Early Childhood development Policies Around the World. Objectives, Conceptual Framework and Methodological Approach. Banco Mundial

Belsky, J. (2005). Child Care and Its Impact on Young Children (0-2). En Encyclopedia of Early Childhood Development. Consulta realizada el 15 de septiembre de 2015. http://www.child-encyclopedia.com/

Bennett, M. y Paredes, R. (2013). Habilidades Cognitivas y Educación Parvularia en Chile.

Bisquerra, R. (2014). Metodología de la investigación educativa. Madrid: La Muralla Bravo y Morales (2012). Caracterización de educadoras de párvulos que se desempeñan en el nivel sala cuna en una muestra de jardines infantiles de Concepción, Chile. Revista Electrónica Actualidades Investigativas en Educación, 12(2), 125. Consulta realizada el 17 de septiembre de 2015. http://www.redalyc.org/pdf/447/44723437009.pdf

Castro, F., Correa, M. y Lira,H. (2006). Currículum y Evaluación Educacional. Chile: Ediciones Universidad del Bío-Bío.

Díaz, M. (2010). Saber didáctico en la Educación Parvularia. Consideraciones para la planificación y evaluación. Santiago: Editorial Andrés Bello. 
López, O. (2013). Los maestros de hoy para los niños del mañana. Revista En Clave Social, 2(2), 80-88.

MINEDUC. (2001). Bases Curriculares de la Educación Parvularia. Santiago de Chile.

MINEDUC. (2014). Estado del Arte de la Educación Parvularia en Chile. Santiago de Chile: Centro de Estudios MINEDUC.

Montero, L. (2001). La construcción del conocimiento profesional docente. Argentina: Homosapiens Ediciones.

Katz, L. (2005). Perspectivas educativas en la primera infancia. Santiago de Chile: Ediciones Lom.

Peralta, M. (2005). Nacidos para ser y aprender. La educación en el periodo más crítico de la vida: los primeros tres años. Buenos Aires: Editorial Infanto Juvenil.

Peralta, M. V. (2004). En la construcción de una pedagogía para párvulos del siglo XXI. Aportes desde Latinoamérica. Madrid: OEI.

Pitluk, L. (2001). El jardín maternal: Una institución educativa. En L.Pitluk (Coord.), Jardín Maternal III, Un desafío a favor de la infancia . Colección 0 a 5, La educación de los primeros años (pp. 6-21). Buenos Aires: Ediciones Novedades Educativas.

Ramírez- Abrahams, P., Patiño- Mora, V. y Gamboa- Vásquez, E. (2014). La educación temprana para niños y niñas desde el nacimiento a los 3 años: Tres perspectivas de análisis. Revista Electrónica Educare, 18(3), 67-90. Consulta realizada el 14 de septiembre de 2015. doi: http://dx.doi.org/10.15359/ree.18-3.5

Zabalza, M. (1996). Calidad en la Educación Infantil. Madrid: Narcea.

Young,M y Fujimoto, G. (2004). Desarrollo infantil temprano: lecciones de los programas no formales. Acción Pedagógica, 13(2), 186-198. Consulta realizada el 10 de septiembre de 2015. http://www.saber.ula.ve/handle/123456789/17211 
Reveco, O. y Mella, O. (2004). Impacto de la Educación Parvularia en la Educación Básica. (versión online). Consulta realizada el 22 de septiembre de 2015. https://www.oas.org/udse/dit/impacto.doc 